\title{
THE PREVALENCE OF INTESTINAL PARASITIC INFESTETION IN A TERTIARY CARE HOSPITAL-A RETROSPECTIVE STUDY
}

\author{
Ganesh Kumar Singh, Kamal Prasad Parajuli, Medhavi Shrestha, Santwana \\ Pandey, Shekhar Chandra Yadav
}

\begin{abstract}
:
Intestinal parasitosis is highly prevalent among the general population in Nepal. This study aimed to evaluate the distribution of intestinal parasites among patients attending Nobel Medical College Teaching Hospital, Biratnagar, Nepal. A total of 5,524 stool samples examined by direct smear and Formal-Ether concentration technique were reported.

The overall prevalence of intestinal parasitic infection was found to be $15.17 \%(\mathrm{M}=15.65 \%$ vs $\mathrm{F}=14.62 \%$ ). The overall prevalence of intestinal parasitosis was found to be highest among patients aged 5-14 years $(20.66 \%)$, followed by elderly people aged $>45$ years $(16.20 \%)$ and least among children aged $<5$ years $(9.09 \%)$. Among various parasites detected, the most common was Entamoeba histolytica (44.86\%) followed by Giardia lamblia (33.65\%), hookworm (10.50\%), Ascaris lumbricoides (5.72\%), Strongyloides stercoralis (4.77\%), Hymenolepis nana (3.34\%), Trichuris trichiura $(0.95 \%)$ and Enterobius vermicularis $(0.23 \%)$ respectively.
\end{abstract}

Keywords: Intestinal parasites; Prevalence; Stool; Infection.

\section{Introduction}

It is estimated that some 3.5 billion people are affected, and that 450 million are ill as a result of Intestinal parasites and protozoan infections worldwide, the majority being children, as they cause iron deficiency anemia, growth retardation in children and other physical and mental health problems. ${ }^{1,2}$

The developing countries are more prone to intestinal and extra-intestinal parasitic diseases causing important public health problems. $^{3}$ Transmission of intestinal parasites is associated with poor personal hygiene which also encourages person to person transmission, poor food hygiene and the presence of flies as well as contaminated drinking water. ${ }^{4}$ In Nepal about $70 \%$ of health problems is due to infectious diseases and diarrheal disease alone is one of the major cause of morbidity and

mortality. 5,6 The prevalence rates of enteric parasitosis reported from Nepal vary from considerably low to nearly one hundred percent $^{7,8,9}$ This variation is probably due to difference in time, place and method used.

There is insufficiency of epidemiological data on the diffusion and prevalence of intestinal parasites in symptomatic patients. The microbiology laboratory of our hospital is receiving an increased number of requests for the analysis of stool specimens for ova and parasites. This trend prompted us to evaluate the distribution of intestinal parasites isolated by our laboratory over a two years period. Authors believe that these studies are important 
as they provide basic data for the control of parasitic infection in future.

\section{Material and methods}

A total of 5,524 samples (Male=2912 and Female=2612) from the outpatient as well as inpatient departments during the period of two years from 1st January 2010 to 31 December 2011 received at the department of microbiology, central laboratory, Nobel Medical College Teaching Hospital, Biratnagar, Nepal were included in the current study. Subjects were divided into age groups $(<5,5-14,15-24,25-44,>45 \mathrm{yrs})$, and gender (Male/female).

The patients were provided wide mouthed clean, dry, properly labeled plastic container for collection of samples and recommend 5 grams of solid or $10 \mathrm{ml}$ of liquid stool. The stool samples were examined within 1-2 hours of collection. Macroscopic examination was done to look for structures like proglottids, scolices, adult tapeworm, Enterobius, Ascaris, Trichuris or hookworm. Unstained saline wet mount preparation was done to detect protozoal tropozoites and helminthic eggs or larvae. Iodine wet mount was done to detect cysts. ${ }^{10}$ The Formal-Ether concentration technique was performed for those cases which were negative by saline preparation method but had strong clinical suspicion of intestinal parasitism. ${ }^{11}$ The findings of stool examination were subjected to analysis by using SPSS version 16

\section{Result}

A total of 5,524 samples were examined of which 2912 were from male and 2612 were from female of which $838(15.17 \%)$ revealed presence of some kind of parasites (Fig.1).
Figure 1: Over all prevalence of parasites $(N=5524)$

Negative $\square$ Positive

$15 \%$

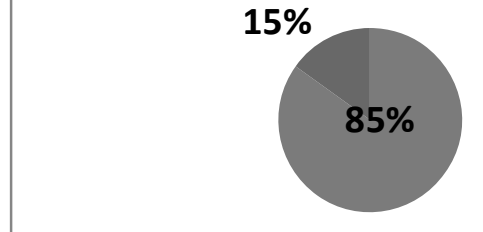

Comparatively parasitic infection was found to be almost equal among males and females (456/2912 vs 382/2612) The overall prevalence of intestinal parasitosis was found to be highest among patients aged 5-14 years (20.66\%), followed by elderly people aged $>45$ years $(16.20 \%)$ and least among children aged $<5$ years $(9.09 \%)$ (Table-1).

\section{Table 1: Age and gender wise distribution of positive cases}

\begin{tabular}{|c|c|c|c|}
\hline Category & $\begin{array}{c}\text { Total Tested } \\
(\mathbf{N = 5 5 2 4 )}\end{array}$ & $\begin{array}{c}\text { Positive } \\
(\boldsymbol{n = 8 3 8})\end{array}$ & $\begin{array}{c}\text { Percentage } \\
(\mathbf{\%})\end{array}$ \\
\hline $\begin{array}{c}\text { Age: }<5 \\
\text { years }\end{array}$ & 1188 & 108 & 9.09 \\
\hline $\begin{array}{c}\text { Age: } 5-14 \\
\text { years }\end{array}$ & 1026 & 212 & 20.66 \\
\hline $\begin{array}{c}\text { Age: } 15-24 \\
\text { years }\end{array}$ & 704 & 98 & 13.92 \\
\hline $\begin{array}{c}\text { Age: } 25-45 \\
\text { years }\end{array}$ & 1470 & 236 & 16.05 \\
\hline $\begin{array}{c}\text { Age: }>45 \\
\text { years }\end{array}$ & 1136 & 184 & 16.20 \\
\hline Male & 2912 & 456 & 15.65 \\
\hline Female & 2612 & 382 & 14.62 \\
\hline
\end{tabular}

Among various parasites detected, the most common was Entamoeba histolytica, (44.86\%) followed by Giardia lamblia (33.65\%), hookworm (10.50\%), Ascaris lumbricoides (5.72\%), Strongyloides stercoralis (4.77\%), Hymenolepis nana (3.34\%), Trichuris trichiura $(0.95 \%)$ and Enterobius vermicularis $(0.23 \%)$ respectively (Figure- 2$)$. 


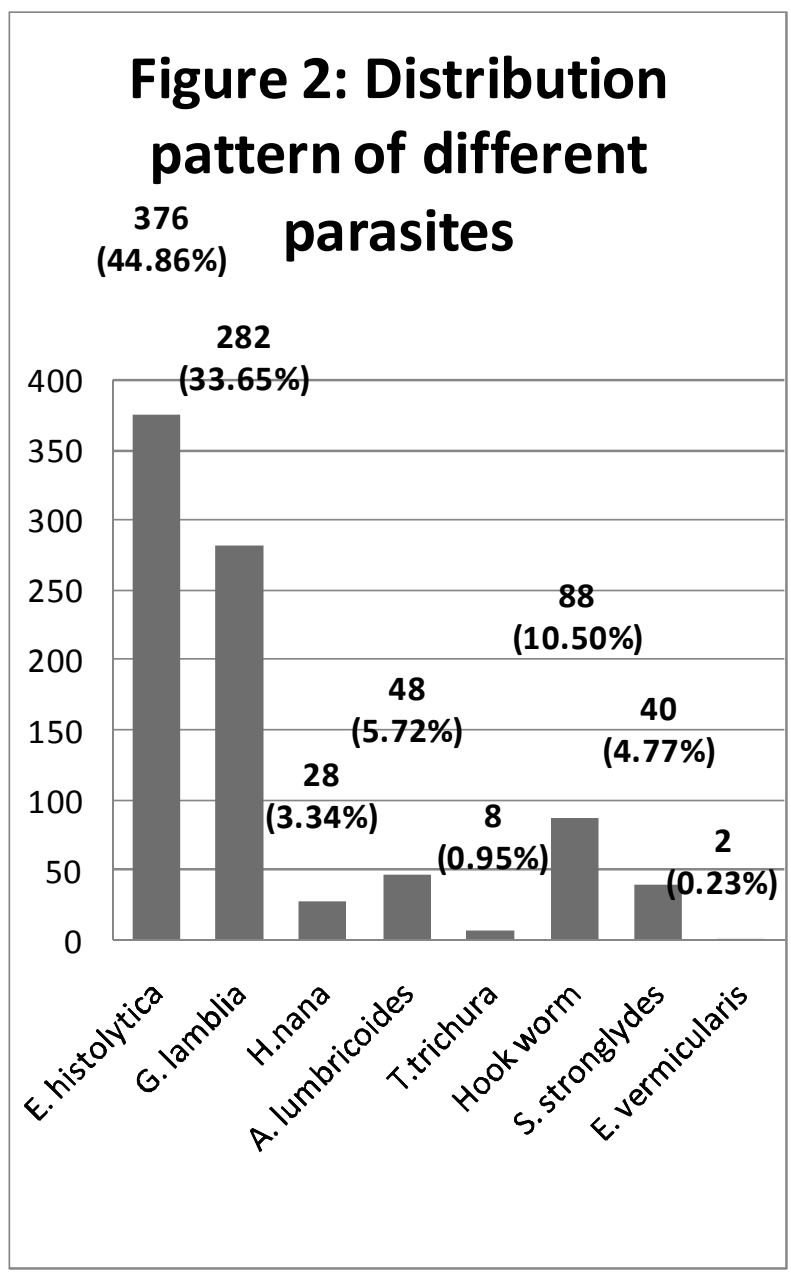

The prevalence of intestinal parasites stratified by age groups is shown in Figure 3 . Statistically significant differences in the frequency of E. histolytica, G. lamblia and $H$. nana was observed according to age with highest prevalence of $E$. histolytica in age group 25-45 years and $G$. lamblia and $H$. nana in age group 5-14 years. The distribution of intestinal parasites stratified by age groups revealed increase in soil transmitted helminthes (S. stercoralis and Hookworm) with age $(p<0.05)$.There was no statistically significant difference in the percentage of $A$. lumbricoides, T. trichura and E. vermicularis according to the age of the patients $(p>0.05)$.

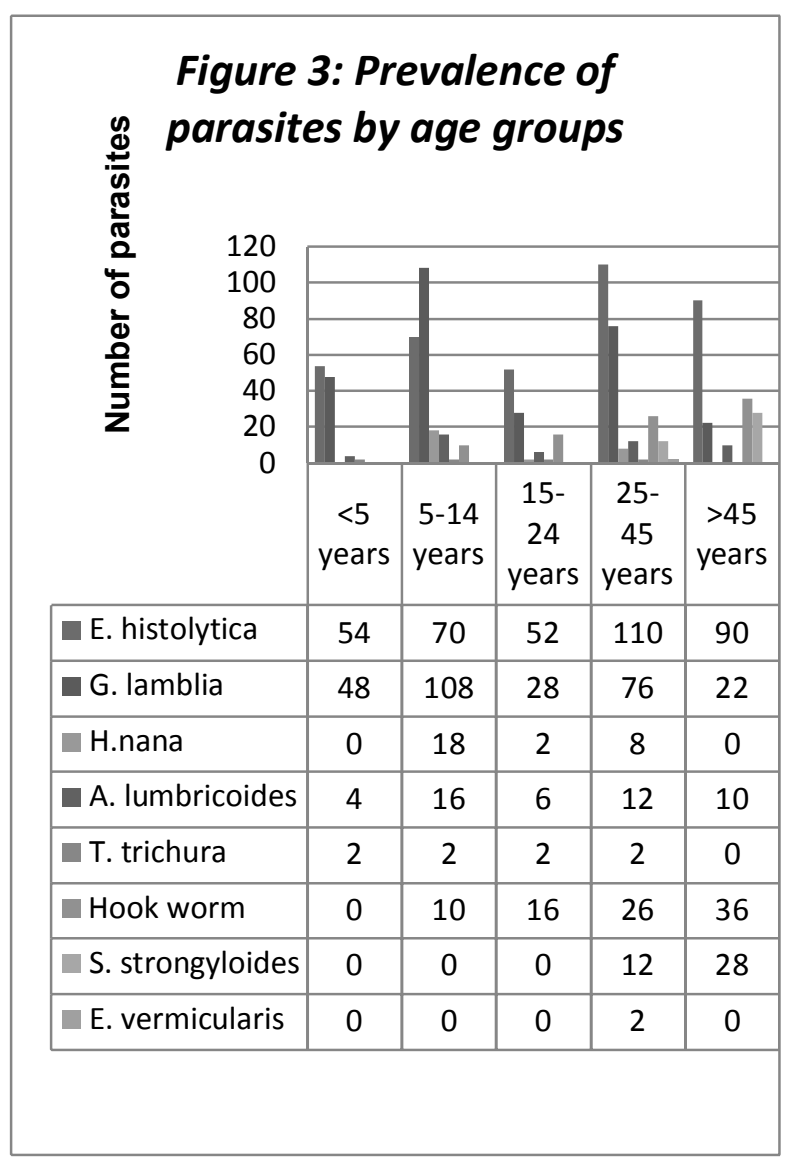

Total is higher than 838 , because a Patient could be infected with more than one parasite species

\section{Discussion:}

The prevalence of intestinal parasitoses found in our study is much lower than that reported earlier from elsewhere in Nepal, but still it seems alarmingly high in comparison to international scenario. ${ }^{12-18}$ This variation is probably due to difference in time, place, method used, health awareness, and living standards.

Gender wise prevalence of parasitic infection was observed almost equal among males and 
females, though slightly higher in males $(15.65 \%$ vs $14.62 \%)$ which shows agreement with reports from Nepal and other countries regarding gender independence of parasitic infection. ${ }^{13,14,19-23}$

Based on the age, prevalence of parasitic infection was highest among patients aged 5-14 years $(20.66 \%)$ followed by $>45$ years $(16.20 \%)$. This finding is similar to the studies done in different parts of Nepal. ${ }^{19,20}$ In contrast it was lowest among children aged $<5$ years $(9.09 \%)$ in our study. High parasitic infection found among school aged children might be due to their unhygienic behavior and lack of sanitation.

The higher infection with E. histolytica may be attributed to poor sewerage system in the community, and the fecal contamination of ground water, the ground water being major source of drinking water in the region. Similarly, higher helminthic infection, particularly by Hookworm and Ascaris, in this study suggests high soil contamination with infective stage of helminths. This report seems similar to that of another study and might be due to rapid, unplanned urbanization, open defecation and other unhygienic conditions and lack of health awareness. ${ }^{19}$ Hookworm infection detected among more than one tenth population in this study might be related to poor farmers residing in the locality who usually work bare foot in the farm, which might have been contaminated with infective stage of hook worm.

Though, the overall prevalence of intestinal parasitosis among the hospital visiting patients is declining, the high detection of parasites like E. histolytica, G. lamblia, Hookworm, S. strongyloides and A. lumbricoides signifies the need of public awareness regarding use of latrine, water source protection from fecal contamination, proper sanitation and hygienic behavior along with the continuity to the mass deworming program.

\section{References:}

1. World Health Organization. Control of Tropical Diseases WHO, 1998; Geneva.

2. Evans AC, Stephenson LS. Not by drugs alone: the fight against parasitic helminths. World Health Forum 1995;16(3):258-261.

3. Andersen PL. Amebiasis. Ugeskr Laeger 2000 Mar;162(11):1537-1541

4. Das Rabindranath, Pradipta Swain Kumar, Biswas R. Prevalence of intestinal parasites \& its association with sociodemographic, environmental \& behavioral factors in children in Pokhara valley, Nepal. Afr J Cln Exper Microbiol 2006; 7(2):106115

5. Bista MB. Infectious diseases in Nepal: a collection of selected publications on communicable diseases including vector-borne diseases 1909 - 2000. 2001.

6. Rai SK, Rai G, Hirai K, Abe A, Ohno Y. The health system in Nepal - an introduction. Env Health Prev Med J 2001a; 6: 1-8.

7. Rai SK, Hirai K, Abe A, et al. Intestinal parasitosis among school children in a rural hilly area of Dhading district, Nepal. Nepal Med College J 2002; 4: 54-8.

8. Estevez EG, Levine JA, Warren J. Intestinal parasites in a remote village in Nepal. J Clin Microbiol 1983; 17: 160-1.

9. Rai SK, Gurung CK. Intestinal parasitic infection in high school children of Birgunj city. J Inst Med (Nepal) 1986; 8: 33-8.

10. Chatterjee KD, Parasitology: 12th ed, Chatterjee Medical Publishers, Calcutta, India, 1995:211.

11. Cheesbrough M, Medical Laboratory Manual for Tropical Countries: Techniques used to identify parasites, London, Butterworths, 1987; 2: 178-97. 
12. Chhetri MK. Parasitic infection in Nepal. J Nepal Med Assoc 1997; 35: 60-5.

13. Rai SK, Bajracharya K, Budhathoki S et al. Status of intestinal parasitosis at TU Teaching Hospital. J Inst Med (Nepal) 1995; 17: 134 -42.

14. Rai CK, Shrestha A, Shah RDP, Rai SK. Study of intestinal parasitosis among patients visiting health care centre in Kathmandu valley. J Nepal Assoc Med Lab Sci 2007; 8: 33-6.

15. Uga S, Rai SK, Kimura K et al. Parasites detected from diarroheal stool smaples collected in Kathmandu, Nepal. Southeast Asian J Trop Med Public Health 2004; 35: 19-23.

16. Nuchprayoon S, Siriyasatien P, Kraivichian K, Porksakorn C, Nuchprayoon I. Prevalence of parasitic infection among Thai patients at the king Chultalongkorn memorial Hospital, Bangkok, Thailand. J Med Assoc Thai 2002; 85: 415-23.

17. Dina AM Zaglool, Yousif AW Khodari, Zohair J. Gazzaz, Khalid O. Dhafar, Hani AS Shaker, Mian U. Farooq. Prevalence of Intestinal Parasites among Patients of Al-Noor Specialist Hospital, Makkah, Saudi Arabia. Oman Medical Journal (2011) Vol. 26, No. 3: 182-185
18. Masucci L, Graffeo R, Bani S, Bugli F, Boccia S, Nicolotti N, Fiori B, Fadda G, Spanu T. Intestinal parasites isolated in a large teaching hospital, Italy, 1 May 2006 to 31 December 2008.Euro Surveill. 2011;16(24):pii=19891.

19. Shakya B, Bhargava D, Shrestha S, Rijal BP. Intestional parasitosis. J Inst Med (Nepal) 2009; 31:13-6.

20. Ishiyama S, Rai SK, Ono K, Uga S. Small scale study on intestinal parasitosis in a remote hilly village in Nepal. Nepal Med Coll J 2003; 5: 28-30.

21. Rai Sk, Matsumara $\mathrm{T}$, Ono $\mathrm{k}$ et al. Intestinal parasitosis in an "unknown disease outbreak" hit rural hilly area in western Nepal. Nepal Med Coll J 2000; 2:61- 4 .

22. Bansal D, Sehgal R, Bhatti HS et al. Intestinal parasites and intra familial incidence in a low socio - economic area of Chandigarh (North India). Nepal Med Coll J 2004; 6: 28-31.

23. Rai K, Sherchand JB, Bhatta DR. Study of enteropathogens and its predisposing factors in gastroenteritis suspected children attending Kanti children Hospital, Kathmandu, Nepal. J Nepal Assoc Med Lab Sci 2004; 6: 48-53.

Address of Correspondence: Ganesh Kumar Singh, Lecturer, Department of Microbiology, Nobel Medical College, Biratnagar. E-mail: ganeshkumarsingh@yahoo.com 